\title{
MUSCULOSKELETAL DISORDERS IN DENTISTRY
}

\author{
Ruby Singla ${ }^{1}$, Hemant Gupta ${ }^{2}$, Inderpreet Kaur ${ }^{3}$, Kapil Singla ${ }^{4}$, Jatinder Singh ${ }^{5}$, Sangeeta Aggarwal ${ }^{6}$ \\ ${ }^{1}$ Sr Lecturer, Department of Periodontics, Adesh Institute of Dental Sciences \& Research, Punjab, India \\ ${ }^{2}$ Prof \& Head, Department of Periodontics, Adesh Institute of Dental Sciences \& Research, Punjab, India \\ ${ }^{3}$ Reader, Department of Prosthodontics, Adesh Institute of Dental Sciences \& Research, Punjab, India \\ ${ }^{4}$ Reader, Department of Prosthodontics, Desh Bhagat Dental College \& Hospital, Punjab, India \\ ${ }^{5}$ Professor \& Head, Department of Community Dentistry, Adesh Institute of Dental Sciences \& Research, Punjab, India \\ ${ }^{6} \mathrm{SMO}$, Department of Conservative Dentistry, Government Dental College \& Hospital, Punjab, India
}

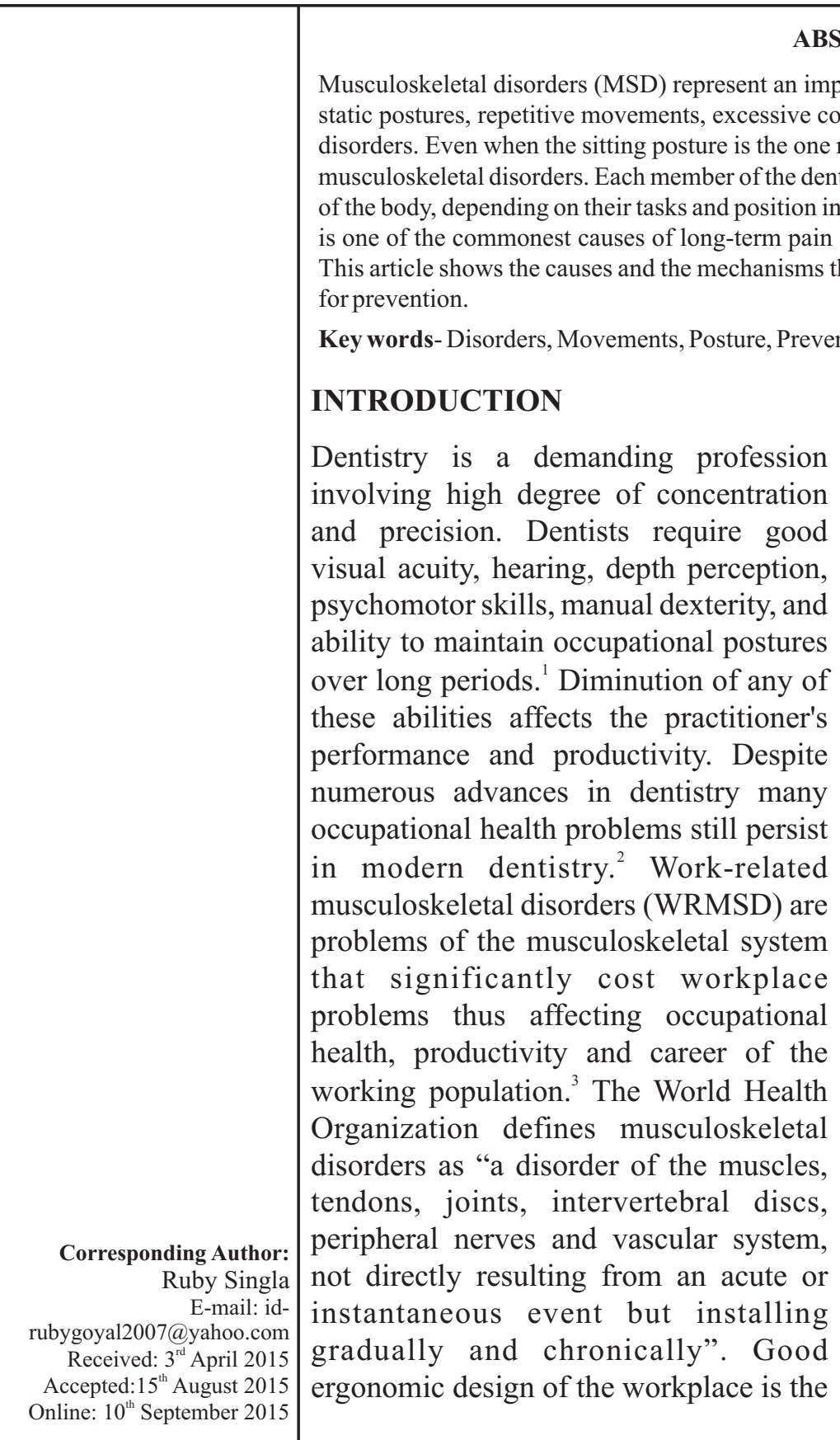

basic requirement for improving musculoskeletal health. ${ }^{4}$

\section{ANATOMY AND PHYSIOLOGY OF THE BACK}

It is important to understand the function of the vertebrae and the muscles supporting the vertebrae. There are three vertebral groups that comprise this twenty-four bone structure: the neck (7 cervical vertebrae), the middle back (12 thoracic vertebrae), and the lower back (5 lumbar vertebrae).

The muscles that connect the upper extremity to the vertebrae column and are of relevance to this study are the latissimus dorsi and the trapezius muscles. The trapezius is a flat, triangular muscle, covering the upper and back part of the neck and shoulders (Gray, 2000). ${ }^{5}$ The angles of the trapezius fibers provide pull in three different directions: up, down, and in toward the center line of the body. The descending part of the right and left trapezius muscle and the latissimus dorsi are a common site of symptomatic pain in dentists. ${ }^{6}$ The latissimus dorsi is a 
triangular, flat muscle which covers the lumbar region and the lower half of the thoracic region, and is gradually contracted into a narrow fasciculus at its insertion into the humerus. ${ }^{5}$ It rises no higher in point of origin than the first lumbar spine. The postures in which dentists sit require over half of the body's muscles to work to hold the body motionless while resisting gravity. The static forces resulting from these postures have been shown to be more taxing than dynamic forces (Ratzon et al, 2000). ${ }^{7}$ Therefore, when the supporting muscles begin to reflect fatigue, a process of pain and discomfort begins and could very well lead to musculoskeletal injury.

\section{WORKING POSTURE IN THE DENTAL SURGERY}

Despite the sitting postures have been recommended as the healthiest and the most correct ones, but the findings of a research done in Timisoara proved that more than $50 \%$ of the dentists that are over 45 years work in dental surgery in orthostatic postures, while those aged between 24 and 35 exclusively prefer the sitting postures. ${ }^{4}$

Orthostatics posture (upright posture) (Figure 1) Although the manual work like the determination of occlusion, some extractions can be performed only in

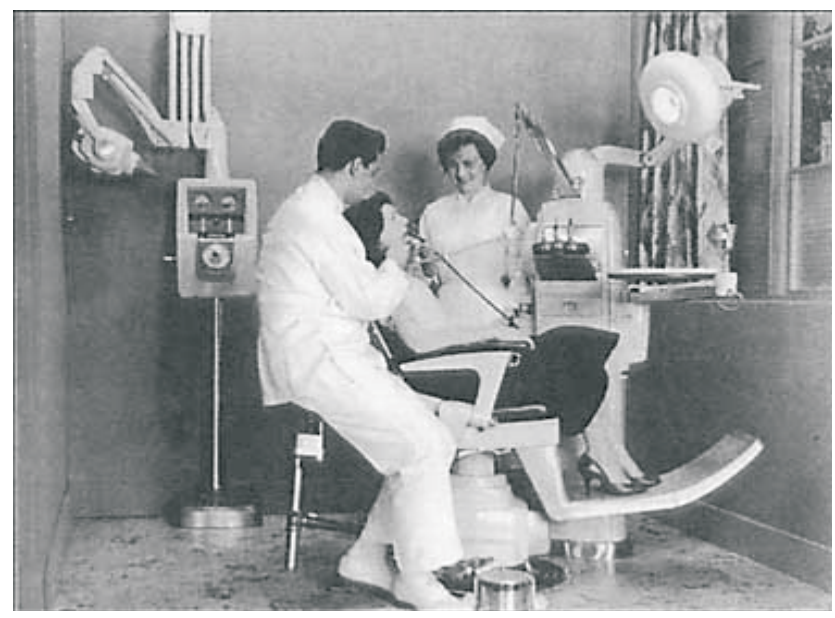

Figure 1: Upright posture $\{\text { Biller 1946 }\}^{20}$

orthostatic posture but it is considered to be more tiring due to a heavier blood flow, body weight distributed on a smaller surface negatively influencing the equilibrium, support only on one leg and diminished accuracy of movements. The effects of a prolonged orthostatic posture include higher heart rate, the energy consumption and static effort higher than in sitting postures, affected osteoarticular system and peripheral venous circulation. ${ }^{4}$

Steady posture (Figure 2) shows a slight forward bend with the neck and head tilted in an effort to get a better view, while the arms are elevated and unsupported. As this posture becomes the normal working position, the muscles responsible for supporting the working posture become stronger and shorter while the

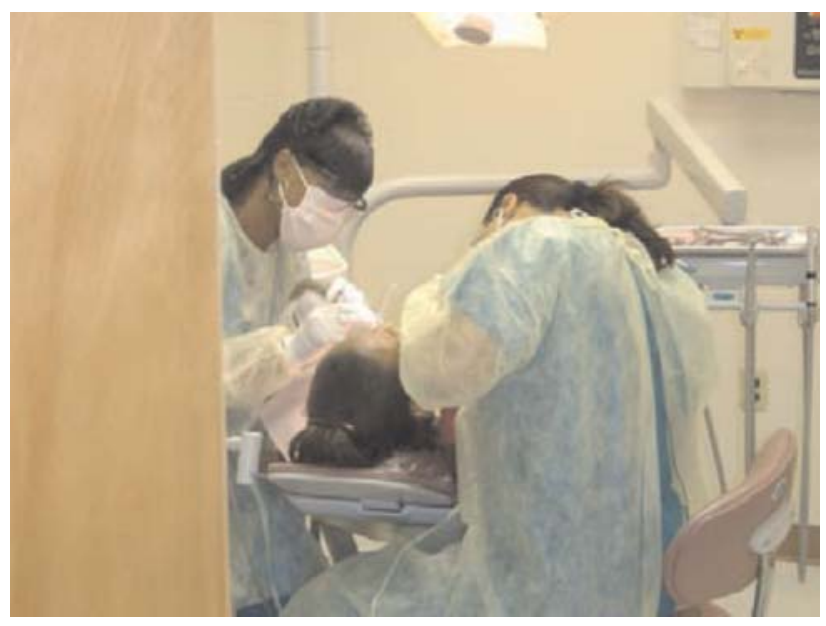

Figure 2: Steady posture

contrasting muscle group becomes weaker and elongated. The stress shortened muscles can then become ischemic and painful. Muscle imbalances in the lower back can also occur when the dentist leans forward repeatedly, causing strain in the low back extensors while making the transverses abdominus weaker. Over time, the body can adapt to these imbalances and this abnormal posture could ultimately lead up to musculoskeletal disorders. ${ }^{8}$

Sitting postures. The correct working postures in the dental surgery are the sitting postures that conform to the following requirements. ${ }^{4}$

- $\quad$ symmetrical postures (Figure 3),

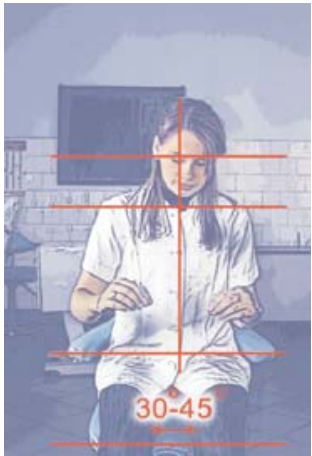

Figure 3

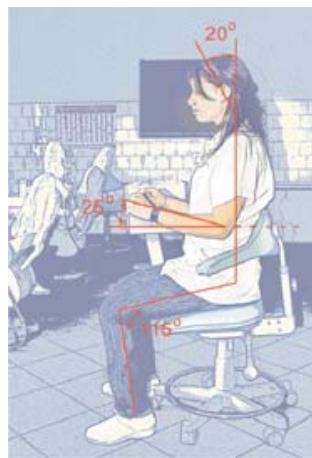

Figure 4 
- all horizontal axes should be parallel

- the legs should be slightly apart $\left(\mathrm{a} 30^{\circ}-45^{\circ}\right.$ angle $)$

- the shank should be perpendicular on the floor

- the upper part of the body should be perpendicular on the chair

- forward movements should be made without curving the spine

- the head could bend $20^{\circ}-25^{\circ}$

- the arms should be close to the body

- the forearms should be nearly horizontal (max. $25 \%$ raised)

- the shank/ thigh should be at $115^{\circ}$

- the soles should be on the floor (Figure 4).

When working in sitting postures a chair is required to support the seat and back (Figure 5). In this situation one should alternate active and passive sitting postures.

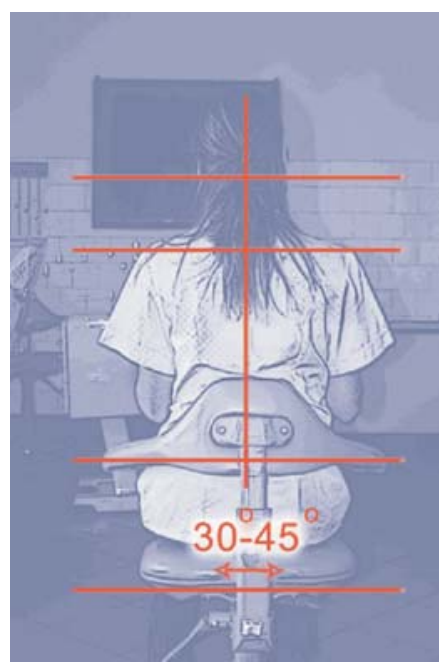

Figure 5

The active posture could be defined as the correct body posture that is maintained by the muscles of the back, the back being leaned forward. This posture cannot be maintained for a very long time. The passive posture is the one in which the back is sustained by the dentist's back of the chair. There are certain moments when the wrong postures cannot be avoided. In wrong postures the oxygen supply in muscles is altered and it is easy to maintain it for a very short time. The supply is determined by the alternative contraction of the muscles, while the blood with residue is removed the muscles relax, and are supplied with oxygenated blood. The muscular pump can function at its best if there is a continuous movement of the muscles that consists in contractions and relaxations. The static postures do not allow consecutive contractions and relaxations. That is why in correct static postures various posture movements should be made in order to determine alternative contraction and relaxation of different muscular groups. If a wrong posture is adopted sooner than 3 or 4 seconds the muscular pump will start its restrictions so that the muscles could not be supplied with the optimum amount of oxygenated blood. This stress can result in ischemia and pain in the overexerted muscles and that is why at that specific moment an adequate muscular relaxation is necessary for the normal functioning of the muscles.

\section{MSDs CLASSIFICATION ${ }^{4}$}

1. Nerve Entrapment Disorders: carpal tunnel syndrome, ulnar neuropathy.

2. Occupational Disorders of the Neck and Brachial Plexus: tension neck syndrome, cervical spondylosis, cervical disc disease, brachial plexus compression.

3. Shoulder disorders: trapezius myalgia, rotator cuff tendonitis, rotator cuff tears, and adhesive capsulitis.

4. Tendonitis of the Elbow, Forearm and Wrist: de Quervain's disease, tendonitis, tenosynovitis, epicondylitis

5. Hand-Arm Vibration Syndrome: Raynaud's disease.

6. Low Back Disorders: Chronic low back pain.

\section{DISCUSSION}

Musculoskeletal disorders are a diverse group of disorders with regard to pathophysiology. In the dental profession, dentists and dental hygienists spend their work days in an awkward, static position performing extremely precise procedures in a 2"x $2 \frac{1}{2}$ " workspace the patient's mouth. Because there is no room for error, a steady hand and a steady, awkward posture must be assumed and maintained. However, maintaining the steady hand and posture comes at a cost to the back, neck and shoulder area of the dentist. Occasional pains from irregular stances or positions are to be expected while they are performing static work. However, when the pain becomes a regular occurrence, cumulative damage could arise leading to debilitating injuries.

Several studies have indicated that back, neck and shoulder pain are a major problem among dentists. 
Finsen et al. (1997) $)^{9}$ reported $65 \%$ and Chowanadisai et al. $(2000)^{10}$ reported $78 \%$. (However, all of these studies focused primarily on the physiological effects of prolonged postures occurring in the neck and shoulder region). According to World Health Organization (WHO), the burden of musculoskeletal disorders can be assessed in terms of problems associated with them, that is the pain and impaired functioning (disability) related to the musculoskeletal system or in relation to the cause such as joint disease or trauma. ${ }^{11}$ Muralidharan D reported high prevalence of musculoskeletal disorders among dental practitioners affecting the daily practice of more than one third. ${ }^{11}$

The high prevalence of musculoskeletal disorders suggests the need to identify the factors predisposing to musculoskeletal disorders among the dental practitioners. This might be due to lack of an ergonomically oriented work practice among the Indian dental practitioners; however further studies need to be conducted in order to make logical conclusions. India has a population of 1.21 billion people and 1,04,603 registered practicing dentists providing oral health care for the people. The dentist population ratio of India is 1:12, 437.46 when compared to the World Health Organization (WHO) recommendation of 1:7500. ${ }^{11}$ Against this background of large population, rising oral health care needs, and inadequate dental manpower, the health and efficiency of the dental care practitioner play a key role in the providing optimal oral health care. ${ }^{11}$

The role of age is controversial. Some authors claim that the frequency of pain remains stable with age. ${ }^{12}$ Others believe musculoskeletal disorders peaks around the sixth decade of life, meaning that the prevalence and severity of pain increases progressively with age. ${ }^{7}$ A third group considers musculoskeletal disorders to be greater in young dentists. ${ }^{13}$ Many researchers have shown that women are more prone to develop musculoskeletal pain than men. ${ }^{13}$ Because dentists spend long hours hunched over their patients with their arms raised and their hands positioned relative to their patients' mouths, unsupported stress is placed on the muscles of the lower back. A study by McGill et al, $(2000)^{14}$ explains how prolonged static contractions of the lumbar erector spine decreases oxygenation levels in the muscle. When this happens, lactic acid and metabolites accumulate and causes the pain that one feel. ${ }^{12}$
An article by Valachi and Valachi $(2003)^{8}$ cited a flowchart of muscle activity and pain leading to a musculoskeletal disorder (Figure 6).

\begin{tabular}{|c|}
\hline Prolonged Static Posture \\
$\Omega$ \\
Muscle Fatigue and Muscle Imbalance \\
$\sqrt{\Omega}$ \\
Muscle Ischemia/Necrosis, Trigger Points and \\
Muscle Substitution \\
$\sqrt{\Omega}$ \\
Pain \\
$\sqrt{\Omega}$ \\
Protective Muscle Contraction \\
$\sqrt{\Omega}$ \\
Nerve Compression, Spinal Disk Degeneration \\
$\sqrt{\Omega}$ \\
Musculoskeletal Disorder
\end{tabular}

Figure 6

Kihara $^{15}$ in a survey of dentists in private clinics found that prevalence of hand and arms, neck and shoulders and low back symptoms differed between three work postures commonly adopted by clinicians. Trunk lateral bending and rotation increased the low back extensor muscle electromyography (EMG) activity.

Morse et $\mathrm{al}^{16}$ reviewed and found static awkward postures involving isometric contractions of trapezius.

Hayes et $\mathrm{al}^{17}$ (2009) found that lack of regular physical exercise was highly associated with lower back pain.

Morse et $\mathrm{al}^{16}$ found self-reported shoulder pain was strongly associated with working above shoulder height and neck symptoms with working positions involving a bent neck posture.

The pain suffered by dentists may lead to reduced productivity in terms of missed time from work or reduced work hours and may also lead to inefficient movements while working, causing an increase in time spent per patient. Therefore, not only will those engaged in dentistry benefit from a reduction of the chronic trauma often associated with the profession, but society as a whole will reap benefits in terms of efficiency and reliability of dentists and their practices. 


\section{PREVENTION METHODS ${ }^{4}$}

1. Adopting a correct working posture.

2. Use of adequate light.

3. Good planning of dental care sessions.

4. Alternative planning of long and short sessions.

5. Alternating the body postures - sitting and upright.

6. Having short breaks after each care session and long coffee or lunch breaks, the sink should be installed at distance.

7. The working day should not be longer than 7 hours.

8. Every 6 weeks a journey should be planned.

9. Sports activities should be practiced for about 45 minutes three times a week.

10. Use of Electromyography (EMG) biofeedback training along with physiotherapy in dental professionals can reduce upper trapezius muscle tension and thereby reduce the work related neck pain. By reducing muscle activity in the neck and shoulder postural stabilizing muscles, EMG biofeedback training would be an effective mode of treatment in dental professionals for the management of work related neck pain. ${ }^{19}$

\section{CONCLUSION}

In conclusion, pain, injury or musculoskeletal disorders are consequences of the working process in dentistry and represent important causes of morbidity and work inefficiency. Research put into evidence the high incidence of disorders resulted from wrong postures. Thus in a survey of 1200 patients, $38 \%$ had disorders of the hands, $14 \%$ had disorders of the arms, $44 \%$ had disorders of the shoulder, $61 \%$ had disorders of the neck and cervical spine, $43 \%$ had disorders of the thoraces spine, $61 \%$ had disorders of the lumbar spine and $10 \%$ had disorders of the legs. ${ }^{12}$ Musculoskeletal disorders reduce work capacity; patients need recovery, which is often expensive, and sometimes patients cannot fully recover and have to end up their professional career. Dentistry is a profession with high risk of developing musculoskeletal disorders.

\section{REFERENCES}

1. KMS Ayers. Self-reported occupational health of general dental practitioners. Occupational Medicine 2009; 59: 142-148.

2. PA Leggat, U Kedjarune and DR Smith. Occupational health problems in modern dentistry: a review. Industrial Health 2007; 45: 611-621.
3. Cruz GD, Ostroff JS, Kumar JV, Gajendra S. Preventing and detecting oral cancer- oral health care providers' readiness to provide health behavior counseling and oral cancer examinations. JAm Dent Assoc 2005; 136: 594-601.

4. Mirella A, Veronica A. Musculoskeletal disorders (MSDS)Consequences of prolonged static postures. Journal of Experimental Medical \& Surgical Research 2007; 4:167-172.

5. Richard L Darke. Gray's Anatomy for students. Ist edition 2005; 50-51.

6. Murtomaa, H. Work-related complaints of dentists and dental assistants. International Archives of Occupational and Environmental Health 1982; 50: 231-236.

7. Ratzon N, Yaros T, Mizlik A, Kanner T. Musculoskeletal symptoms among dentists in relation to work posture. Work 2000; 15: 153-158.

8. Valachi B, Valachi K. Mechanisms leading to musculoskeletal disorders in dentistry. J Am Dent Assoc 2003; 123: 1344-1350.

9. Finsen L, Christensen H, Bakke M. Musculoskeletal disorders among dentists and variation in dental work. Applied Ergonomics 1998;29:119-125.

10. Chowanadisai S, Kukiattrakoon B, Yapong B, Kedjarune U, Leggat P. Occupational health problems of dentists in Southern Thailand. Int Dent J 2000; 50:36-40.

11. Muralidharan D. Musculoskeletal Disorders among Dental Practitioners:Does It Affect Practice? Epidemiology Research International 2013; 1-6.

12. Lehto, T, Helenius H. and Alaranta H. Musculoskeletal symptoms of dentists assessed by a multidisciplinary approach. Community dent oral epidemiol 1991; 19: 38-44.

13. Harutunian K. Ergonomics and musculoskeletal pain among postgraduate students and faculty members of the School of the University of Barcelona (Spain). A cross-sectional study. Med Oral Pathol Oral Cir Bucal 2011; 16: 425-429.

14. McGill S, Hughson R, Parks K. Lumbar erector spinae oxygenation during prolonged contractions; implications for prolonged work. Ergonomic 2000; 43: 486-493.

15. Kihara T. Dental care works and work-related complaints of dentists. Kurume Med J 1995; 42: 252-257.

16. Morse T, Bruneau H, Dussetschleger J. Musculoskeletal disorders of the neck and shoulder in the dental professions. Work 2010; 35: 429.

17. Hayes MJ, Smith DR, Cockrell D. Prevalence and correlates of musculoskeletal disorders among Australian dental hygiene students. Int J Dent Hyg 2009; 7: 176-181.

18. Morse T, Bruneau H. Musculoskeletal disorders of the neck and shoulder in dental hygienists and dental hygiene students. J Dent Hyg 2007; $81: 10$.

19. Mohamed Faisal. C. K. Does electromyography biofeedback training reduce work-related neck pain? Int J Physiother Res 2014; 2: 706-11.

20. Biller, F. Occupational hazards in dental practice. Oral Hyg. 1946; 36: 1194-1201

Source of Support: Nil, Conflict of Interest: None Declared 